Tohoku J. exp. Med., 1980, 131, 127-134

\title{
Studies on Porcine Pancreatic Elastase Activity. II. Immunoreactive Elastase Level during Acute Hemorrhagic Pancreatitis in Pigs
}

\author{
Yasuyuki Nakajima, Seiki Matsuno, Noboru Noto, \\ Yoichi SaItoh and Toshio Sato \\ The First Department of Surgery, Tohoku University School \\ of Medicine, Sendai 980
}

\begin{abstract}
Nakajima, Y., Matsuno, S., Noto, N., Sattoh, Y. and Sato, T. Studies on Porcine Pancreatic Elastase Activity. II. Immunoreactive Elastase Level during Acute Hemorrhagic Pancreatitis in Pigs. Tohoku J. exp. Med., 1980, 131 (2), $127-$ 134 - Acute hemorrhagic pancreatitis was produced in pig to study serum concentration of elastase and its physiological role. Pancreatitis was induced in two groups of young pigs by the injection of autologous bile. One group was injected with autologous bile $(0.5 \mathrm{ml} / \mathrm{kg})$ at high pressure, and the second group was injected at low pressure $\left(100 \mathrm{~cm} \mathrm{H}_{2} \mathrm{O}\right)$. Then femoral blood, portal blood and thoracic lymph were sampled at scheduled time intervals. The control level of immunoreactive elastase was around $90 \mathrm{ng} / \mathrm{ml}$ in each site, which significantly increased beginning $15 \mathrm{~min}$ after bile injection; the level of immunoreactive elastase was higher in the thoracic lymph duct than in the femoral and portal vein. The total and free elastase of both groups in pancreatic tissue were significantly decreased in pancreatitis, and an abundance of immunoreactive elastase was found in the ascites. The increasing pattern of immunoreactive elastase and amylase after bile injection was very similar. Therefore, the level of immunoreactive elastase was considered to be inadequate to determine the grade of severity of pancreatitis as well as the level of amylase which is already known. _ - immunoreactive elastase; acute hemorrhagic pancreatitis in pig
\end{abstract}

In acute pancreatitis, elastase is believed to destroy elastic fiber on the wall of the blood vessel, eventually causing hemorrhage (Geokas et al. 1968a, b; Schneider et al. 1962). Various results were reported regarding the serum concentration of elastase in acute pancreatitis: Rinderknecht et al. (1968) and Satake et al. (1974) reported a fall and Kasahara et al. (1975) a rise. The discrepancy may stem from the different methods of determining elastase activity. In our preceding report, we offered an improved procedure of radioimmunoassay (R.I.), with results fairly satisfactory in the determination of elastase in porcine serum (Nakajima et al. 1980). In the present study, we produced acute hemorrhagic pancreatitis in pigs and measured the serum elastase determined by the improved procedure of R.I. and studied its physiological role and clinical significance.

Received for publication, March 28, 1979. 


\section{Materials and Methods}

Production of porcine acute pancrestitis. Group 1: In young pigs $(20-35 \mathrm{~kg}, n=5$, $\delta 3$, \& 2), pentobarbital $(20 \mathrm{mg} / \mathrm{kg})$ was intravenously injected, then a tracheostomy was performed following an insertion of endotracheal tube and breathing was maintained with the respirator. After immediate cannulation of the femoral vein and thoracic lymph duct, laparotomy was performed following a cannulation from the hilus of the splenic vein into the portal vein. Acute pancreatitis was induced by high-pressure injection of autologous bile $(0.5 \mathrm{ml} / \mathrm{kg})$ into the main pancreatic duct, which was then ligated. During the experiment, the normal saline $(15 \mathrm{ml} / \mathrm{kg} / \mathrm{hr})$ was given from the femoral vein. Group 2: In young pigs $(27-37 \mathrm{~kg}, n=6, \delta 4, \& 2)$, acute pancreatitis was induced by the same method as described in Group 1, except for the pressure of injection at $100 \mathrm{~cm} \mathrm{H}_{2} \mathrm{O}$.

Preparation of test material. Blood and lymph were sampled from the femoral vein, the portal vein and the thoracic lymph duct through the cannulation up to $5 \mathrm{hr}$ after the injection of autologous bile, and the samples were immediately centrifuged and sera were stored at $-20^{\circ} \mathrm{C}$. At $5 \mathrm{hr}$ after bile injection, ascites and pancreatic tissue were obtained. The pancreatic tissue was partly used for histological examination, and partly frozen, dried and stored at $-20^{\circ} \mathrm{C}$ for determination of activities of elastase and amylase.

Measurements. The concentrations of elastase in serum, lymph, ascites and pancreatic tissue were determined by R.I. In the cases of pancreatic tissue, the esterolytic activity of elastase was also measured by a $\mathrm{pH}$-stat autotitrator using $\mathrm{N}$-benzoyl-L-alanine methylester (BAME, Aldrich Chemical Co., Milwaukee) as the substrate in the manner described in the preceding report (Nakajima et al. 1980). In determining the total elastase activity in pancreatic tissue, various concentrations of trypsin (Sigma Co., St. Louis) were added to homogenate of pancreatic tissue in $0.05 \mathrm{M}$ Tris-HCl buffer, $\mathrm{pH} \mathrm{8.0,} \mathrm{at} \mathrm{room} \mathrm{temperature} \mathrm{to}$ activate proelastase into active elastase. Activity of free elastase was measured without addition of trypsin. Activity of amylase were determined by Caraway's method.

\section{Results}

Changes in amylase level. In Group 1, amylase levels were significantly increased within $15 \mathrm{~min}$ after bile injection in the femoral and portal veins and the thoracic lymph duct. The patterns of increase of amylase in the femoral and portal veins were almost the same, each attaining a plateau $2 \mathrm{hr}$ after bile injection, with its level five times as high as the control level. By contrast, amylase in thoracic lymph duct increased to the level higher than that in femoral and portal veins $1 \mathrm{hr}$ after bile injection, almost attaining a plateau after $3 \mathrm{hr}$ with its level nearly 13 times as high as the control level (Fig. 1). Amylase activity in pancreatic tissue decreased with pancreatitis to almost one-third of the normal pancreatic tissue. At the time of slaughter, amylase in the ascites revealed a high concentration of $150,984 \pm 82,831$ (mean \pm s.D.). In Group 2, the concentration of amylase began to rise significantly $5 \mathrm{~min}$ after bile injection in femoral and portal blood and in thoracic lymph duct. Each level of amylasein Group 2 was lower than in Group 1, but the pattern of increase was indistinguishable from those in Group 1 (Fig. 2).

Changes in elastase level. In Group 1, the level of immunoreactive elastase, like that of amylase, began to rise significantly 15 min after bile injection in both femoral and portal blood, attaining a plateau after $1 \mathrm{hr}$ with a level $5-6$ times as high as the control level. Also in thoracic lymph duct, immunoreactive elastase began to rise significantly $15 \mathrm{~min}$ after bile injection, revealing a pleateau after $3 \mathrm{hr}$, 


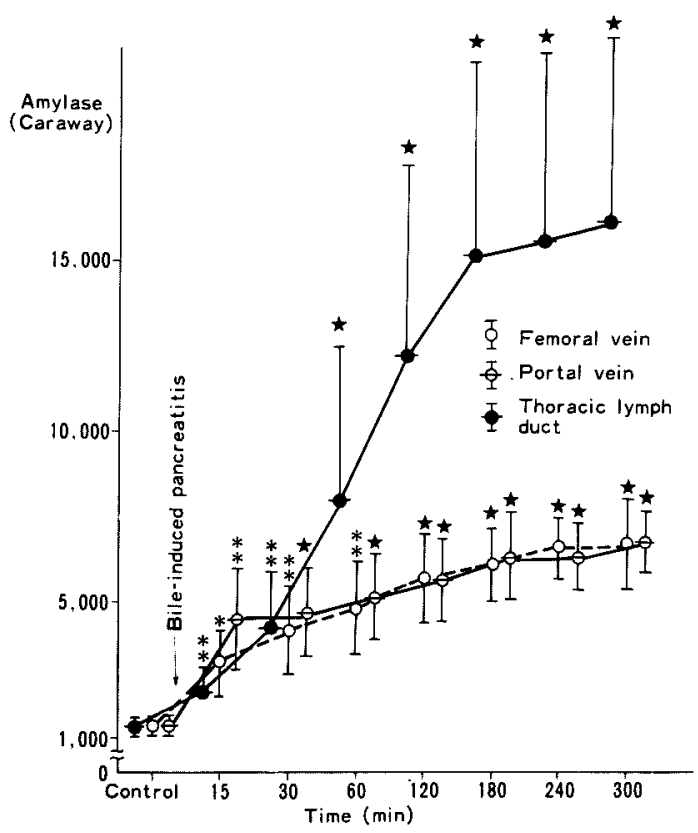

Fig. 1. Change of amylas concentration in plasma and lymph after injection of bile. Vertical lines represent standard deviations. Values are based on experiments in 5 pigs.

$*, p<0.10 ; * *, p<0.05 ; \star, p<0.005$ (compared with control).

with a level 12-13 times as high as the control level, and the elevation of the level was distinctly more remarkable than in the blood (Fig. 3). Hourly measurement of the lymph flow showed no significant difference in volume from the control (Table 1). In group 2, the level of immunoreactive elastase, like amylase, began to rise significantly in femoral and portal blood and in thoracic lymph duct from 5 min after bile injection (Fig. 4). Although each level of immunoreactive elastase in group 2 was lower than in group 1, the pattern of increase was almost the same between the two groups. In the determination of the concentration of trypsin to activate the proelastase in the pancreatic tissue into elastase, trypsin of more than $1 \mathrm{mg}$ fully activated the proelastase in $50 \mathrm{mg}$ of pancreatic tissue. Esterolytic activity of pancreatic tissue in pancreatitis revealed decreases in free elastase and total elastase to $13.9 \pm 3.0$ and $62.9 \pm 35.4 \mathrm{BAME} \mu \mathrm{mole} / \mathrm{min} / \mathrm{mg}$ dry weight (mean \pm s.D.), which were respectively decreased to $1 / 4$ to $1 / 5$ of the control levels. Furthermore, esterolytic activity was not found in either serum, lymph or ascites, and the addition of a modicum $(5 \mu 1)$ of serum, lymph or ascites to elastase was found to inhibit the esterolytic activity of elastase within several min. The concentration of elastase in pancreatic tissue determined by R.I. revealed a significant decrease with pancreatitis which was from $7.7 \pm 1.1 \mu \mathrm{g} / \mathrm{mg}$ to $2.2 \pm 1.9 \mu \mathrm{g} / \mathrm{ml}$ (mean \pm s.D.) for free elastase $(p<0.005)$, and from $18.6 \pm 1.4 \mu \mathrm{g} / \mathrm{mg}$ to $3.5 \pm 3.8 \mu \mathrm{g} / \mathrm{mg}$ (mean \pm s.D.) for total elastase $(p<0.005)$. The concentration of immunoreactive 


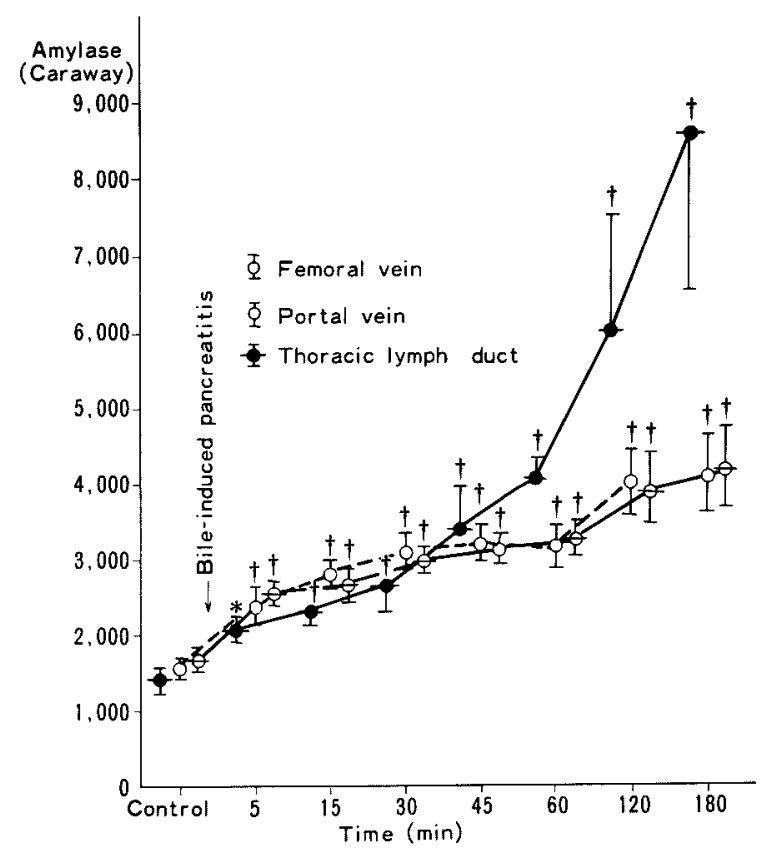

Fig. 2. Change of amylase concentration in plasma and lymph after injection of bile at the low pressure $\left(100 \mathrm{~cm} \mathrm{H}_{2} \mathrm{O}\right)$. Vertical lines represent standard deviations. Values are based on experiments in 6 pigs.

*, $p<0.01 ; \dagger, p<0.005$ (compared with control).

elastase in the ascites as well as the amylaser evealed a high level of $14,712 \pm 15,381$ $\mathrm{ng} / \mathrm{ml}$ (mean \pm s.D.).

Histological findings. Histological examination of pancreatic tissue at $5 \mathrm{hr}$ after injection of bile revealed a gross feature of acute hemorrhagic pancreatitis in all pigs such as interstitial edema, cellular infiltration, parenchymal hemorrhage (Fig. 5) or partial destruction of blood vessel walls (Fig. 6).

\section{Discussion}

It has been presumed that in acute hemorrhagic pancreatitis, elastase with its specific property of digesting elastin destroys the elastic fiber on the wall of the pancreatic blood vessel, inducing hemorrhage (Geokas et al. 1968a,b). Many reports stated that the concentrations of free and total elastase in pancreatic tissue were decreased in pancreatitis though the degrees of decrease reported varied probably due to difference of the method of measurement used (Geokas et al. 1968a; Satake et al. 1974). However, some peculiar behaviors of elastase binding inhibitor in R.I. and in bioassay (Kaplan and Dugas 1969) were reported; in R.I., antielastase antibody has positive cross-reaction with $\alpha_{1}$-antitrypsin-elastase, but negative with $\alpha_{2}$-Macroglobulin-elastase (Katayama and Fujita 1974; Geokas et al. 1977 ), while in bioassay, $\alpha_{1}$-antitrypsin-elastase does not exhibit esterolytic activity, 


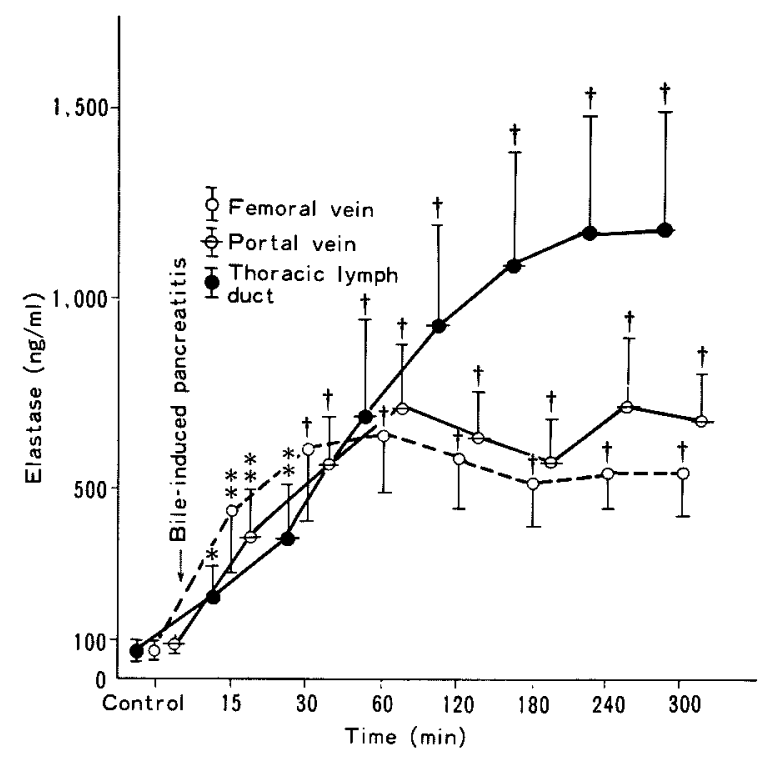

Fig. 3. Change of immunoreactive elastase in plasma and lymph after injection of bile. Vertical lines represent standard deviations. Values are based on experiments in 5 pigs.

$*, p<0.025 ; * *, p<0.01 ; \dagger, p<0.005$ (compared with control).

TABLE 1. Thoracic lymph duct flow $(\mathrm{ml})$

\begin{tabular}{|c|c|c|c|c|c|c|c|c|}
\hline \multirow{2}{*}{ Dog No. } & \multirow{2}{*}{ Sex } & \multirow{2}{*}{$\begin{array}{c}\text { Weight } \\
(\mathrm{kg})\end{array}$} & \multicolumn{6}{|c|}{ Collection periods } \\
\hline & & & Control & $1 \mathrm{hr}$ & $2 \mathrm{hr}$ & $3 \mathrm{hr}$ & $4 \mathrm{hr}$ & $5 \mathrm{hr}$ \\
\hline 1 & $\mathbf{M}$ & 35 & 60 & 52 & 65 & 85 & 65 & 58 \\
\hline 2 & $\mathbf{F}$ & 27 & 120 & 90 & 54 & 60 & 65 & 90 \\
\hline 3 & $\mathbf{F}$ & 20 & 90 & 87 & 75 & 70 & 75 & 80 \\
\hline 4 & $\mathbf{M}$ & 25 & 32 & 20 & 18 & 20 & 18 & 21 \\
\hline 5 & $\mathbf{M}$ & 25 & 90 & 61 & 85 & 65 & 55 & 40 \\
\hline \multicolumn{2}{|c|}{ Mean } & & 78.4 & 62.0 & 59.4 & 60.0 & $55.6^{*}$ & 57.8 \\
\hline
\end{tabular}

* $p<0.10$.

but $\alpha_{2}$-macroglobulin-elastase shows some activity (Bieth et al. 1970; Cohen 1975). Despite of different behaviors of the inhibitors in R.I. and in bioassay, free and total elastase in pancreatic tissue were significantly decreased in our experimental pancreatitis. On the other hand, the level of serum elastase in pancreatitis were reported to rise by Kasahara et al. (1975) and to fall by Satake et al. (1972, 1974). But these results remains in doubt, because they did not exclude the influence of serum inhibitors. In fact, our study revealed that porcine serum and lymph showed no esterolytic activity and also they inhibited the esterolytic activity of elastase. These results suggest that a large amount of inhibitor exists in the serum and that elastase is bound to the inhibitors in the serum.

On the basis of our method of R.I. (Nakajima et al. 1980) and anatomical 


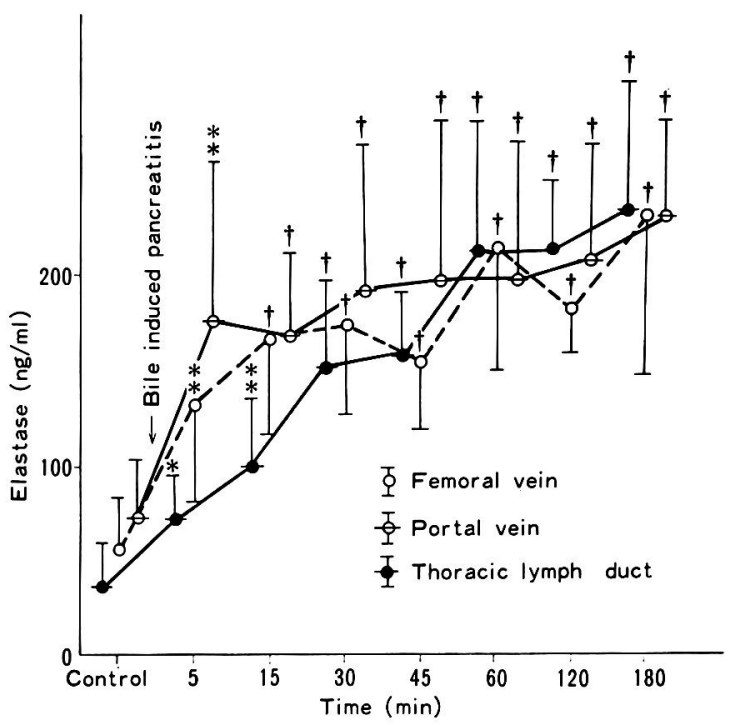

Fig. 4. Change of immunoreactive elastase in plasma and lymph after injection of bile at the low pressure $\left(100 \mathrm{~cm} \mathrm{H}_{2} \mathrm{O}\right)$. Vertical lines represent standard deviations. Values are based on experiments in 6 pigs.

*, $p<0.025$;**, $p<0.01 ; \dagger, p<0.005$ (compared with control).

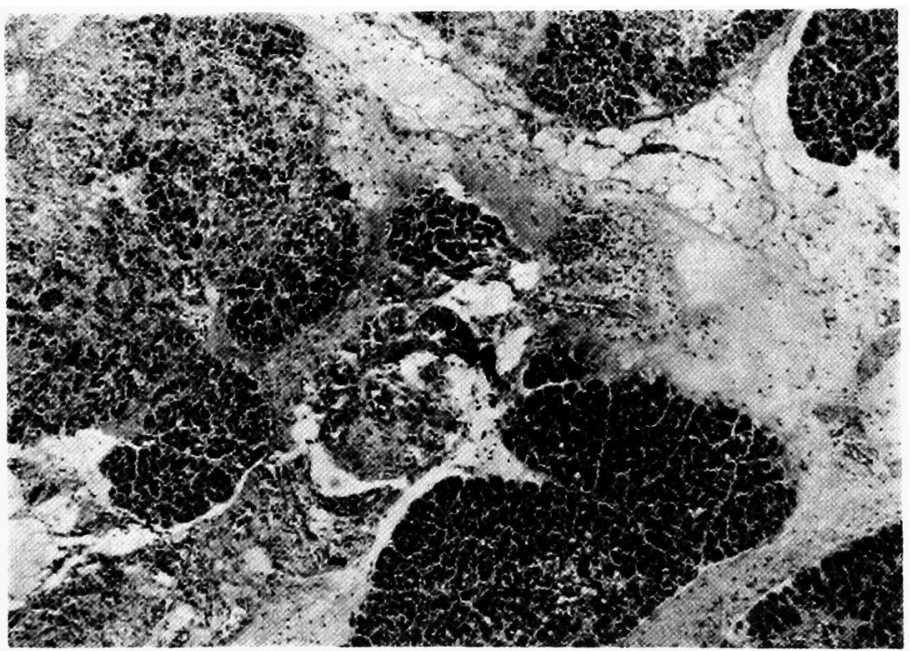

Fig. 5. Necrosis and interstitial hemorrhage in the pancreatic tissue. Hematoxylin and eosin stain. $\times 22$.

analogy of pancreas (Thorpe and Frey 1971), we chose the pig as experimental animal to determine the elastase level in serum and lymph in pancreatitis. It has already been reported that amylase escapes in abundance into the thoracic lymph duct (Vega et al. 1967; Dreiling 1970). The experimental finding that concentra- 


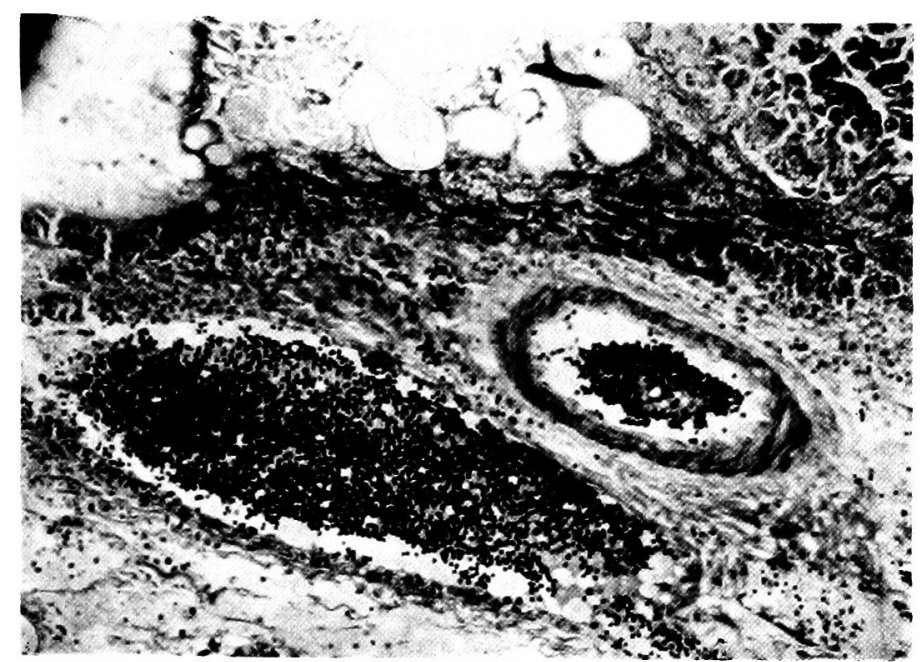

Fig. 6. Destruction of elastic fibers of venule wall in the pancreatic tissue. Azan Mallory stain. $\times 55$.

tions of also amylase and elastase were high not only in thoracic lymph but also in the ascites after the induction of pancreatitis suggests that pancreatitis may allow these enzymes to escape in abundance into the blood and concomitantly into the abdominal cavity and lymph duct. Hourly level-changes in elastase in individual pigs were also close to those in amylase. Experimental pancreatitis produced by bile injection with high pressure rapidly presented a picture of severe hemorrhagic pancreatitis in each pig. Another trial in which relatively slow progress of pancreatitis was induced with bile injection at a reduced pressure $\left(100 \mathrm{~cm} \mathrm{H}_{2} \mathrm{O}\right)$ showed that increases of the levels of amylase and elastase were comparatively lower both in serum and lymph but similar in pattern. Initially we thought that if elastase escapes in abundance into the blood only at the time of acute hemorrhagic or severe pancreatitis and plays a significant role in the progress of the disease, then the determination of its blood level would help to diagnose and treat the acute hemorrhagic pancreatitis. Against our expectation, however, the present study showed, that changes in level of elastase were quite similar to those of amylase, indicating that the determination of the blood level of elastase is clinically insufficient for judging severity of pancreatitis. Further efforts are desirable to make clear the relation between elastase and its inhibitors $\left(\alpha_{1}-\mathrm{AT}, \alpha_{2}-\mathrm{M}\right)$. Also it is desirable to extend the study to edematous pancreatitis to examine the significanc of the change in level of elastase in pancreatitis.

\section{References}

1) Bieth, J., Pichoir, M. \& Metais, P. (1970) The influence of $\alpha_{2}$-macroglobulin on the elastolytic and esterolytic activity of elastase. Fed. Europ. Biochem. Soc. Letters, 8, 319-321.

2) Cohen, A.B. (1975) The interaction of $\alpha_{1}$-antitrypsin with chymotrypsin, trypsin and 
elastase. Biochim. biophys. Acta, 391, 193-200.

3) Dreiling, D.A. (1970) The lymphatics, pancreatic ascites, and pancreatic inflammatory disease. Amer. J. Gastroent., 53, 119-131.

4) Geokas, M.C.,, Murphy, D.R. \& Mckenna, R.D. (1968a) The role of elastase in acute pancreatitis. Arch. Path., 86, 117-126.

5) Geokas, M.C., Rinderknecht, H., Swanson, V. \& Haverback, B.J. (1968b) The role of elastase in acute hemorrhagic pancreatitis in man. Lab. Invest., 19, 235-239.

6) Geokas, M.C., Brodrick, J.W., Johnson, J.H. \& Largman, C. (1977) Pancreatic elastase in human serum determination by radioimmunoassay. J. biol. Chem., 252, 61-67.

7) Kaplan, H. \& Dugas, H. (1969) Evidence that the activity of elastase is not dependent on the ionization of its N-terminal amino group. Biochem. biophys. Res. Comm., 34, $681-685$.

8) Kasahara, K., Carballo, J.R., Takada, Y., Appert, H.E. \& Howard, J.M. (1975) Elastase levels during bile-induced pancreatitis in dogs determined by radioimmunoassay. Surg. Gyne. Obstet., 141, 347-351.

9) Katayama, K. \& Fujita, T. (1974) Studies on biotransformation of elastase. III. Effect of elastase-binding proteins in serum on the disappearance of 131I-labelled elastase from blood. Biochem. biophys. Acta, 336, 165-177.

10) Nakajima, Y., Matsuno S., Noto, N., Saitoh, Y. \& Sato, T. (1980) Studies on porcine pancreatic elastase activity (Part I) Radioimmunoassay of porcine pancreatic elastase. Tohoku J. exp. Med., 131, 119-126.

11) Rinderknecht, H., Geokas, M.C., Silverman, P. \& Haverback, B.J. (1968) Determination of elastolytic activity in blood of normal subjects and patients with acute pancreatitis. Clin. chim. Acta, 19, 89-95.

12) Satake, K., Carballo, J., Appert, H.E. \& Howard, J. (1972) Plasma elastolytic enzyme activity in pancreatic disease. Arch. Surg., 104, 62-63.

13) Satake, K. Reichman, J, Carballo, J., Appert, H.E. \& Howard, J.M. (1974) Plasma levels of elastase, trypsin and their inhibitors in bile induced pancreatitis in the dog. Ann. Surg., 179, 58-62.

14) Schneider, I.J., Tindel, S., Molnar, J. \& State, D. (1962) Elastase-induced hemorrhagic pancreatitis. Gastroenterology, 42, 779.

15) Thorpe, C.D. \& Frey, C.F. (1971) Experimental pancreatitis in pigs. Arch. Surg., 103, 720-723.

16) Vega, R.E., Appert, H.E. \& Howard, J.M. (1967) Effects of secretin in stimulating the output of amylase and lipase in the thoracic duct of the dog. Ann. Surg., 166, 9951001. 